\title{
Hemiarch versus total aortic arch replacement in acute type A dissection: a systematic review and meta-analysis
}

\author{
Shi Sum Poon, Thomas Theologou, Deborah Harrington, Manoj Kuduvalli, Aung Oo, Mark Field \\ Thoracic Aortic Aneurysm Service, Department of Cardiac Surgery, Liverpool Heart and Chest Hospital, Liverpool, UK \\ Correspondence to: Mark Field. Thoracic Aortic Aneurysm Service, Department of Cardiac Surgery, Liverpool Heart and Chest Hospital, Thomas \\ Drive, Liverpool, L14 3PE, UK. Email: mark.field@lhch.nhs.uk.
}

\begin{abstract}
Background: Despite recent advances in aortic surgery, acute type A aortic dissection remains a surgical emergency associated with high mortality and morbidity. Appropriate management is crucial to achieve satisfactory outcomes but the optimal surgical approach is controversial. The present systematic review and meta-analysis sought to access cumulative data from comparative studies between hemiarch and total aortic arch replacement in patients with acute type A aortic dissection.

Methods: A systematic review of the literature using six databases. Eligible studies include comparative studies on hemiarch versus total arch replacement reporting short, medium and long term outcomes. A meta-analysis was performed on eligible studies reporting outcome of interest to quantify the effects of hemiarch replacement on mortality and morbidity risk compared to total arch replacement.

Result: Fourteen retrospective studies met the inclusion criteria and 2,221 patients were included in the final analysis. Pooled analysis showed that hemiarch replacement was associated with a lower risk of postoperative renal dialysis [risk ratio $(\mathrm{RR})=0.72 ; 95 \%$ confidence interval $(\mathrm{CI}): 0.56-0.94 ; \mathrm{P}=0.02 ; \mathrm{I}^{2}=0 \%$ ]. There was no significant difference in terms of in-hospital mortality between the two groups $(\mathrm{RR}=0.84$; 95\% CI: $\left.0.65-1.09 ; \mathrm{P}=0.20 ; \mathrm{I}^{2}=0 \%\right)$. Cardiopulmonary bypass, aortic cross clamp and circulatory arrest times were significantly longer in total arch replacement. During follow up, no significant difference was reported from current studies between the two operative approaches in terms of aortic re-intervention and freedom from aortic reoperation.

Conclusions: Within the context of publication bias by high volume aortic centres and non-randomized data sets, there was no difference in mortality outcomes between the two groups. This analysis serves to demonstrate that for those centers doing sufficient total aortic arch activity to allow for publication, excellent and equivalent outcomes are achievable. Conclusions on differences in longer term outcome data are required. We do not, however, advocate total arch as a primary approach by all centers and surgeons irrespective of patient characteristics, but rather, a tailored approach based on surgeon and center experience and patient presentation.
\end{abstract}

Keywords: Hemiarch replacement; total arch replacement; acute type A dissection; meta-analysis

Submitted Mar 22, 2016. Accepted for publication May 04, 2016.

doi: 10.21037/acs.2016.05.06

View this article at: http://dx.doi.org/10.21037/acs.2016.05.06

\section{Introduction}

Within cardiac surgery, acute type A aortic dissection is an inherently lethal surgical emergency and remains a challenging condition associated with high mortality and morbidity (1). In most patients, the aortic dissection process frequently extends through the arch and the conventional treatment has been hemiarch replacement leaving the downstream aorta untouched $(2,3)$. Several study groups, with the aim to reduce the risk of re-intervention and to obliterate the false lumen, recommended a more extensive approach involving total replacement of aortic arch with possible elephant trunk in selected patients $(4,5)$. This 
complicated procedure posed a great challenge to cardiac surgeons, as the technique of total arch replacement requires a certain level of expertise and experience and the long-term outcomes are not well established.

It is not surprising that there are no randomized controlled trials in this setting as ethical approval would not be forthcoming. A recent registry study, GERAADA (6) based in Germany presents the largest registry worldwide documenting patients undergoing surgery for acute type A dissection. The surgical outcomes between total and hemiarch replacement were compared and the data suggested that a more aggressive approach could be applied without higher early peri-operative risk. Despite recent enthusiasm and the increased utilization of the more extensive approach, many cardiac surgeons remain divided over the issue of the extent of graft replacement and there is a lack of robust clinical data comparing total arch replacement with the conventional approach of hemiarch replacement.

The present systematic review and meta-analysis aims to formally access cumulative data from the literature comparing hemiarch and total aortic arch replacement in patients with acute type A dissection. We aim to access the possible mortality and morbidity cost of open distal anastomosis and ascending surgery with hemiarch replacement versus a more extensive total aortic arch replacement with frozen elephant trunk in patients with acute type A aortic dissection.

\section{Methods}

\section{Literature search strategy}

An electronic search was performed on the following database: PubMed, Ovid Medline, Scopus science direct, Embase, Web of Knowledge, The Cochrane Library from January 2000 to February 2016 using MeSH terms. To achieve maximum sensitivity of search strategy and identify all relevant studies, we combined the terms 'total arch' or 'extensive replacement' or 'hemiarch' or 'proximal repair' or 'arch replacement' or 'aortic replacement' or 'arch repair' or 'limited ascending replacement' or 'open distal anastomosis' or 'stent' or 'frozen elephant trunk' AND 'acute type A dissection' or 'DeBakey type 1 aortic dissection' as either key words or MeSH terms. The publications were limited to English language and human subjects. Case reports, abstracts, expert opinions, editorial comments, review articles, studies without full texts were excluded to maintain consistency of studies. Some additional studies were identified from the reference list of the studies.

\section{Selection criteria}

Eligible studies encompass comparative studies allowing the assessment of short, medium and long-term outcomes. All studies comparing hemiarch and total aortic arch replacement directly were included. Hemiarch replacement is defined as the proximal arch repair beyond the level of the innominate artery without involving the arch vessels, and total arch replacement is the replacement of supra-aortic vessels as an island or individual branched grafts. Type of participants includes adult patients more than 18 years old presenting with acute type A aortic dissection. All duplicates were removed and where multiple observational studies were published by a single institution, the largest and most informative study with complete follow up data was chosen. The authors from the studies included were contacted to retrieve any information required.

\section{Data extraction and critical appraisal}

After initial screening and evaluation of records by two independent reviewers, data on all full-text articles were independently collected and reviewed by two investigators (SS Poon and T Theologou) when potential abstracts were selected. The qualities of papers were assessed independently by authors for suitability, consistency, and adequacy of study design and patient selection according to the Cochrane handbook for Systematic Reviews of Intervention. We followed the recommendation for quality and bias assessment using the Newcastle-Ottawa Score (NOS) (7). This scale uses a star-based rating system and a score of $0-9$ was given to each study $(9=$ lowest risk of bias; $0=$ highest risk of bias) to assess bias on three levels: selection, comparability and outcomes. A score of $\geq 7$ indicates the absence of substantial bias. The scoring is performed by two independent authors. Finally, before the extracted data were analyzed, any discrepancies were resolved by consensus and the final results were reviewed by senior investigators ( $M$ Field, D Harrington, $M$ Kuduvalli and A Oo) Data were extracted and stored within a database spreadsheet (Microsoft Excel and Word).

\section{Statistical analysis}

A meta-analysis was performed by combining results from all selected studies reporting the incidence of outcome of 


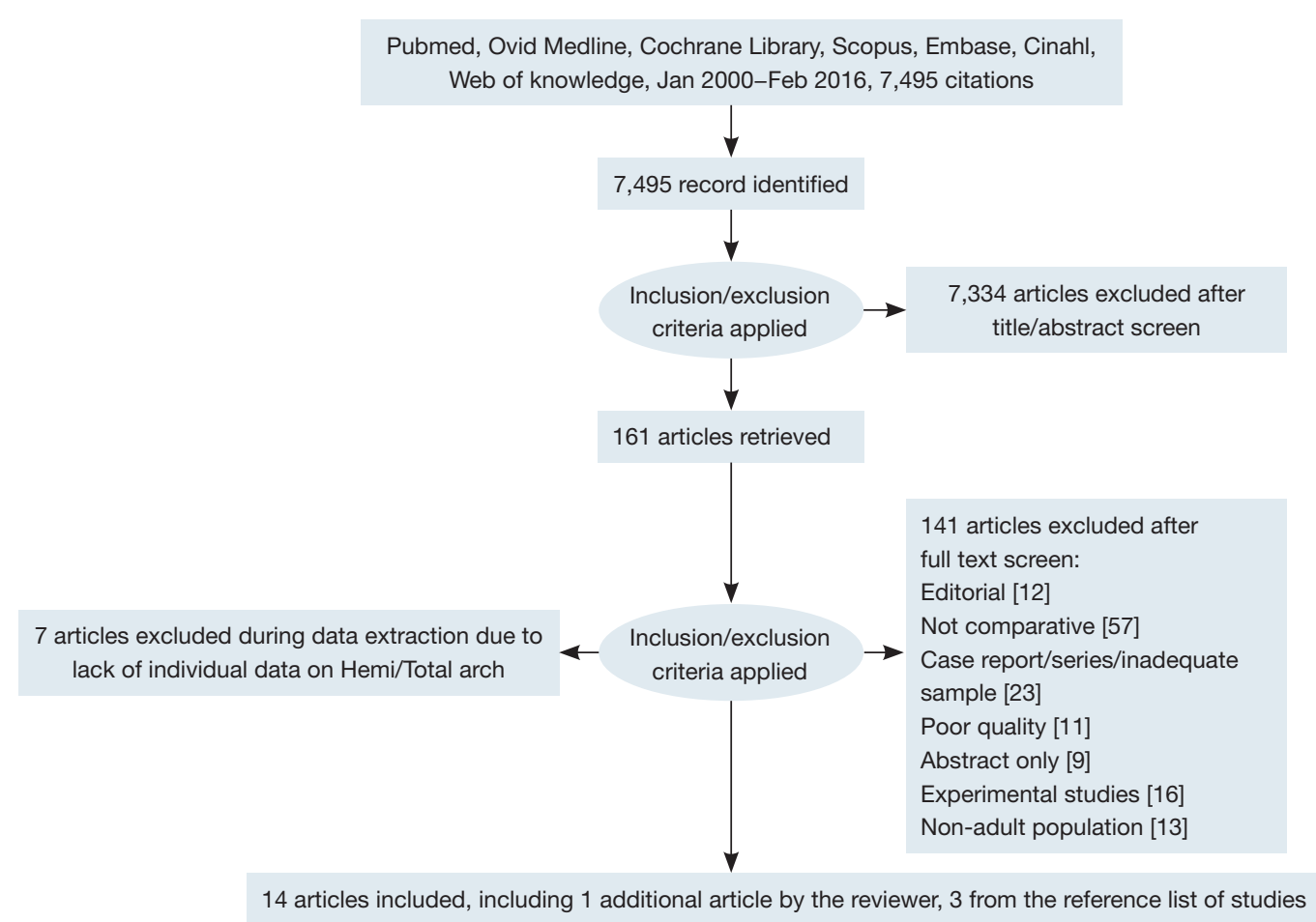

Figure 1 Preferred Reporting Items for Systematic reviews and Meta-analyses (PRISMA) flow chart detailing the selection process and final inclusion of articles.

interest. In the present study, assessment of studies was performed using fixed effect model with inverse variance where it was assumed that there were clinical variations between studies. Dichotomous data were presented in the form of risk ratios (RRs) as a summary of statistics and effect measure with $95 \%$ confidence interval (CI). RRs were derived from the relative frequencies from the studies where available. For continuous data, the mean difference was used as an effect measure instead. Assessment of heterogeneity within the data set was performed using chi-squared test $\left(X^{2}\right)$. $\mathrm{I}^{2}$ test was used to estimate the percentage of total variation across studies that are due to heterogeneity rather than chance. $\mathrm{I}^{2}$ can be readily calculated as $\mathrm{I}^{2}=100 \% \times(\mathrm{Q}-\mathrm{df}) / \mathrm{Q}$ where $\mathrm{Q}$ is Cochran's heterogeneity statistics and $\mathrm{df}$ the degree of freedom. All $\mathrm{P}$ value was two sided. Given the importance of late remodeling in stented arch grafts, pooled hazard ratio (HR) was used to aggregate time-to-event outcomes (freedom from aortic reoperation) using method as described by Tierney et al. (8). The data were derived from studies presenting Kaplan-Meier curve and/or the numbers at risk. HR is estimated using the number of events and the numbers at risk during a particular interval. Taking all time intervals and censoring into account and using the equation as described by Tierney et al., a pooled HR was obtained. Publication bias was assessed using funnel plots comparing log risk estimates with their standard errors. Begg rank correlation and Egger regression test were used to assess funnel plot asymmetry qualitatively. All statistical analysis was conducted using Review Manager (Revman) 5.3 Copenhagen (The Nordic Cochrane Centre, The Cochrane Collaboration, 2014) and Comprehensive Meta-analysis version 3 .

\section{Results}

\section{Quantity and quality of evidence}

After applying selection criteria, 14 comparative studies were retrieved. The selection process is presented in Figure 1 according to the Preferred Reporting Items for Systematic reviews and Meta-analyses (PRISMA) checklist (9). All 14 studies included were retrospective observational studies, including 1,435 patients who underwent hemiarch replacement and 786 total arch replacements, giving a total of 2,221 patients. An overview of the studies was shown in Table 1 . 


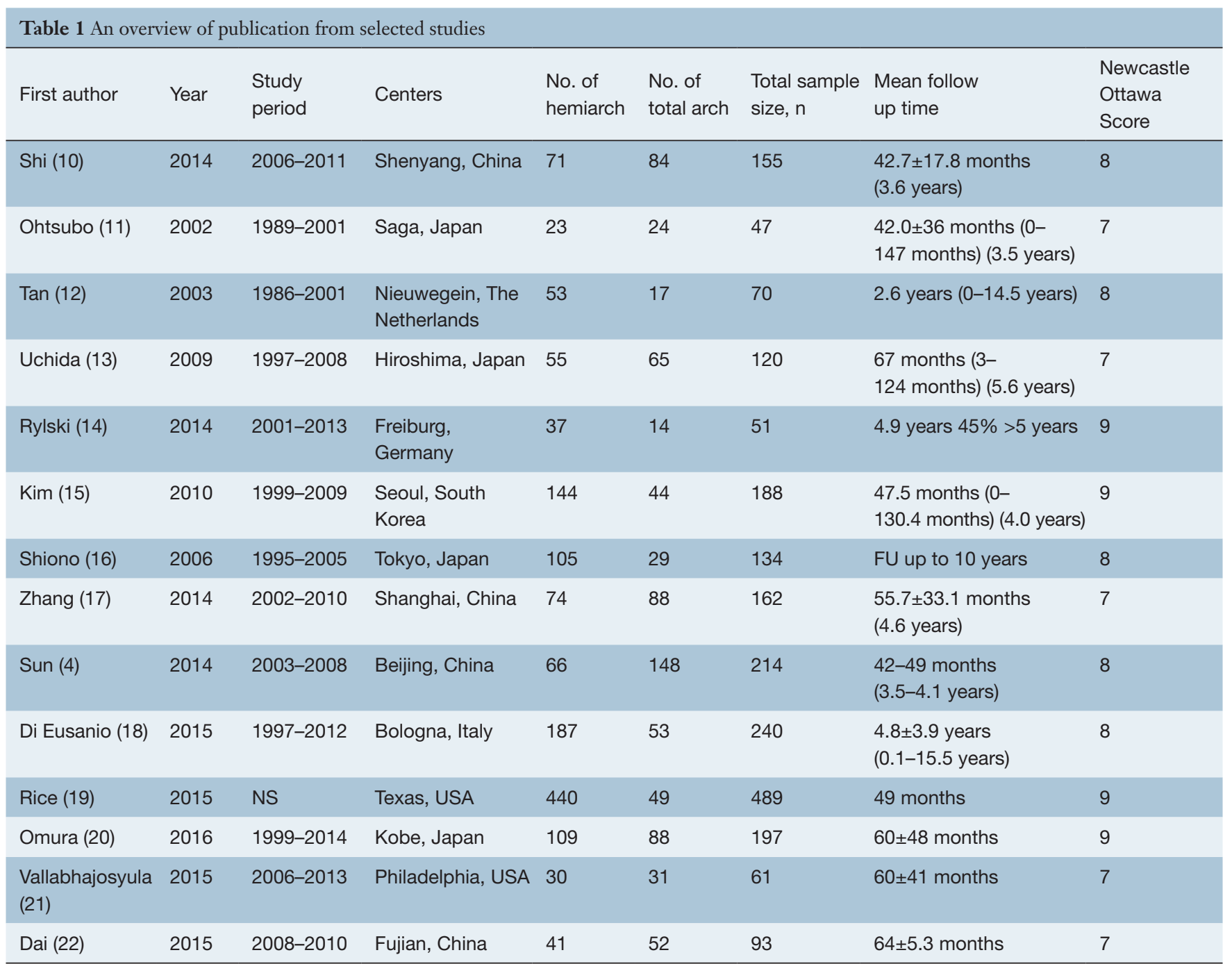

\section{Basic demographics}

Baseline characteristics such as age, male sex, diabetes, hypertension, history of cerebrovascular accident and renal dysfunction, cardiogenic shock and the extent of dissection were summarized in Tables 2,3.

\section{Surgical technique}

For hemiarch replacement, the arch was transected obliquely with the removal of most part of the small curvature of the arch followed by open distal anastomosis. In patients undergoing total arch replacement, the reimplantation of supra-aortic vessels can be done 'en bloc' as an island or vessels anastomosed individually via branched or trifurcated graft. Some centres introduced an intraluminal stent graft into the true lumen of the distal arch using open aortic technique. The graft was crossclamped and antegrade perfusion was resumed through a side branch. Hemiarch replacement was performed when the intimal tear is localized along the ascending aorta or the lesser curvature of the transverse arch. In patients with an intimal tear localized along the greater curvature close to the supra-aortic vessels, total arch replacement was performed. Concomitant stent graft was deployed in eight studies $(4,10,13,17,18,20-22)$. In total arch replacement with frozen elephant trunk, the deployment of stent graft was described differently between studies. In brief, the stent graft was delivered in an antegrade fashion into the true lumen of the descending thoracic aorta. Once the stent graft is properly landed, the distal aorta incorporating 


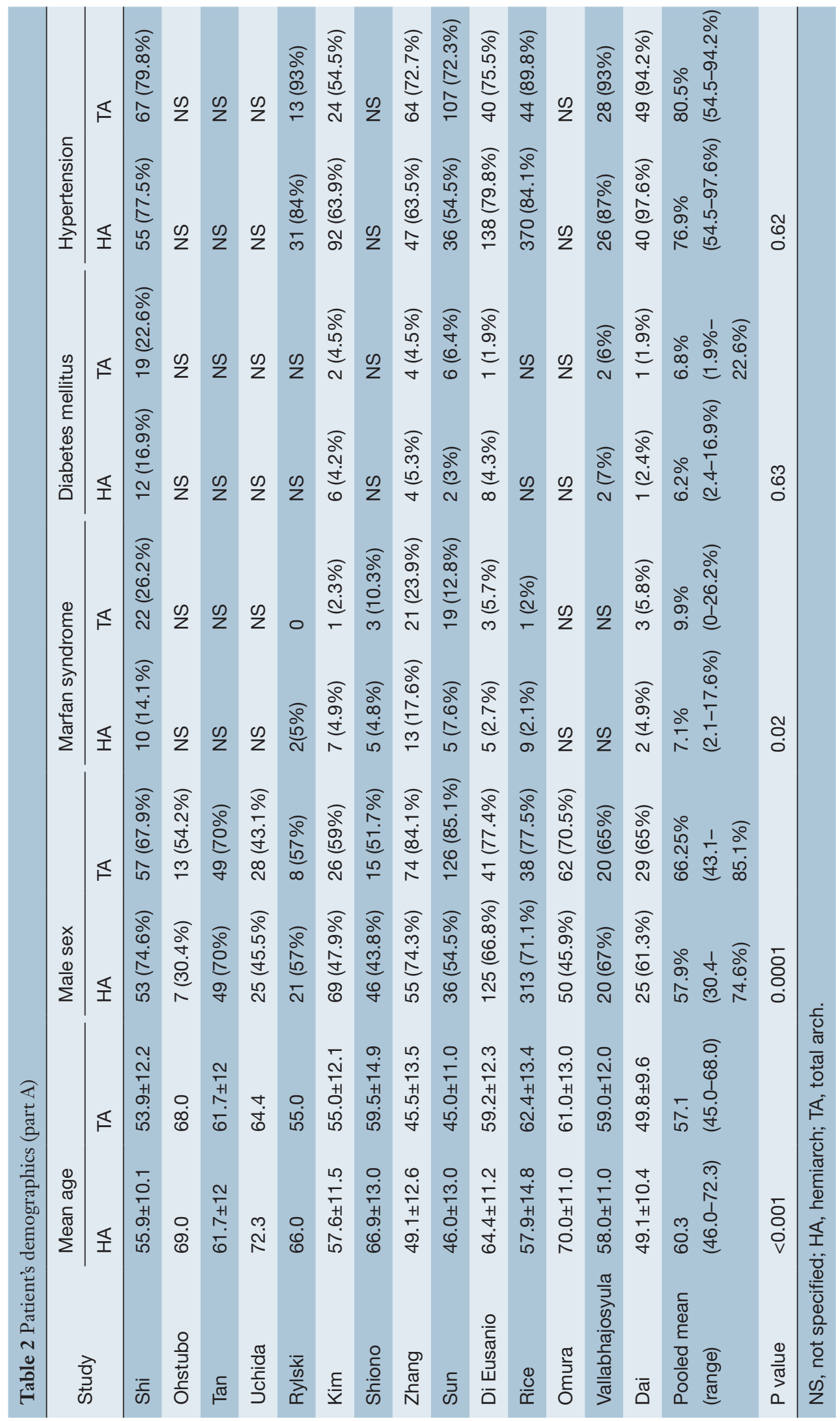




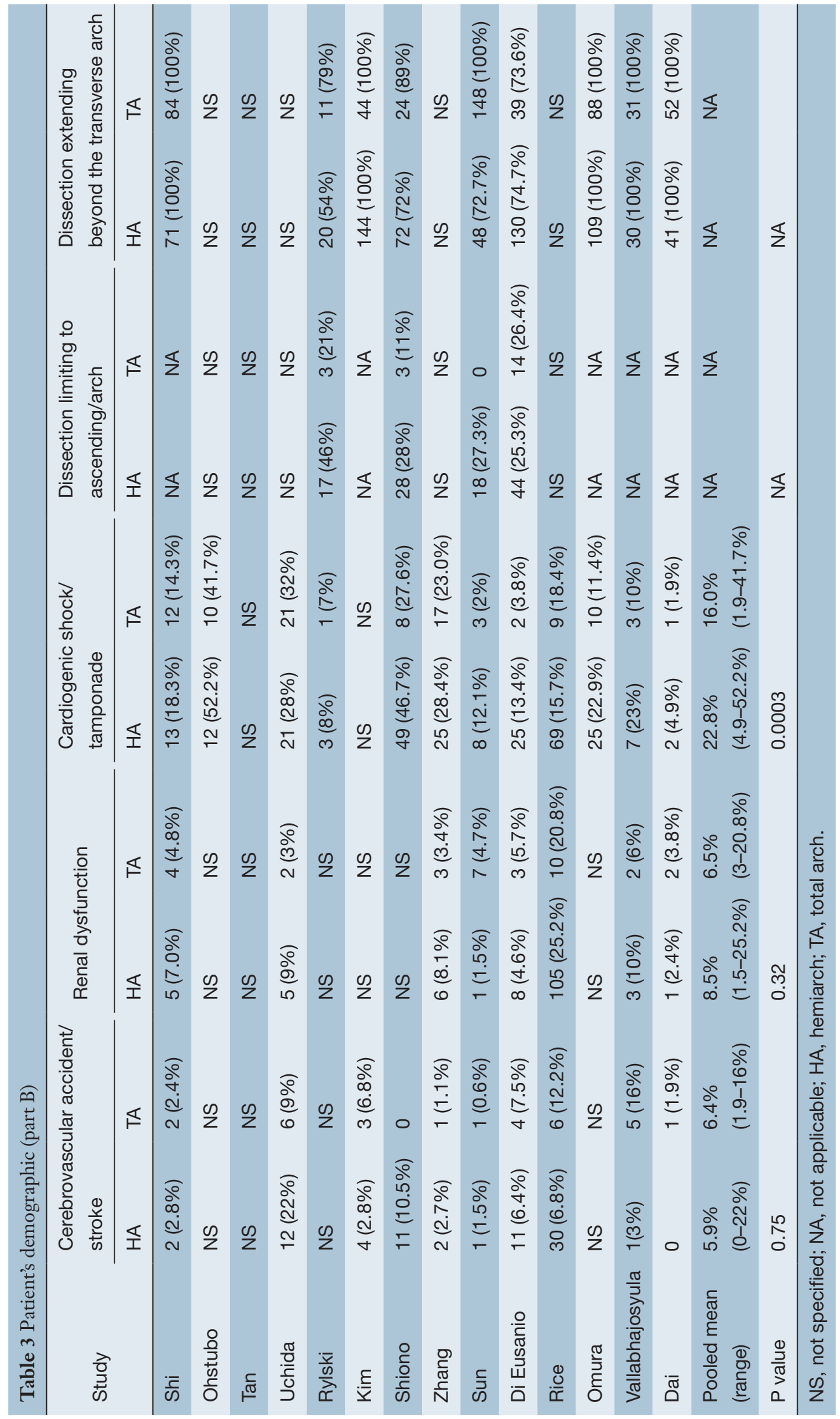


the stent graft was securely anchored to the distal trunk of the branched prosthetic graft using the open aortic procedure. The use of ball-shaped sizer into the true lumen of the descending aorta under transesophageal ultrasound guidance has been described $(13,17)$. The neuroprotective strategies are summarized in Table 4.

\section{Primary outcomes}

\section{Mortality}

Pooled analysis from 14 studies showed no significant differences in terms of in-hospital mortality between hemiarch (HA) and total arch replacement (TA), RR $=0.84 ; 95 \%$ CI: $0.65-1.09 ; \mathrm{P}=0.20 ; \mathrm{I}^{2}=0 \%$. These results are presented in the forest plot, shown as Figure 2. The mortality rate ranged from $3.60-24.1 \%$ for hemiarch replacement and $3.85-28.57 \%$ for total arch, as shown in Figure 3.

\section{Secondary outcomes}

\section{Neurological events}

The incidence of temporary and permanent neurological deficit was reported in 7 and 11 studies respectively. Temporary neurological dysfunction is defined as any the following clinical presentation such as the transient loss of orientation, slurred speech, poor response to command or any focal neurological deficits that resolved completely during follow up. Permanent neurological dysfunction is defined as any post-operative neurological deficits resulting from intraoperative procedure that did not resolve completely such as coma and stroke, confirmed by radiography or clinically by neurology consultation. From the available data, there were no significant differences between the two groups (temporary: $\mathrm{RR}=0.77 ; 95 \%$ CI: $0.56-1.07 ; \mathrm{P}=0.13, \mathrm{I}^{2}=0 \%$; permanent: $\mathrm{RR}=0.82$; 95\% CI: 0.52-1.31; $\mathrm{P}=0.42 ; \mathrm{I}^{2}=15 \%$ ) (Figures 4,5 ). A further subset analysis for new-onset stroke from permanent neurological dysfunction did not demonstrate any differences between the two groups $(\mathrm{RR}=0.88 ; 95 \% \mathrm{CI}$ : $0.48-1.62 ; \mathrm{P}=0.68 ; \mathrm{I}^{2}=0$ ).

\section{Renal dialysis, ventilation $>72$ hours, re-operation for bleeding}

Based on a pooled analysis on ten studies, the incidence of post-operative renal dialysis was significantly lower in hemiarch replacement $(\mathrm{RR}=0.72$; 95\% CI: 0.56-0.94; $\mathrm{P}=0.02$; $\mathrm{I}^{2}=0 \%$ ) (Figure 6). Post-operative ventilation $>72$ hours and re-operation for bleeding were reported in five and eight studies and there was no significant difference between the two groups $(\mathrm{P}=0.14$ and 0.45 respectively).

\section{Operative times}

The duration of cardiopulmonary bypass time (MD $=47.86 \mathrm{~min} ; 95 \%$ CI: 44.37-51.35; P<0.00001; $\left.\mathrm{I}^{2}=97 \%\right)$, cross clamp time $(\mathrm{MD}=18.68 \mathrm{~min}$; $95 \% \mathrm{CI}: 5.94-31.43$; $\left.\mathrm{P}<0.0001 ; \mathrm{I}^{2}=95 \%\right)$ and circulatory arrest time (MD $=10.73 \mathrm{~min} ; 95 \%$ CI: 3.39-18.07; $\mathrm{P}=0.004 ; \mathrm{I}^{2}=97 \%$ ) were significantly longer in total arch replacement. These results are shown in Table 5 respectively.

\section{Aortic re-operation (proximal and distal)}

Overall the rate of aortic reoperation for proximal and distal aorta was $5.6 \%$. Follow up studies from 12 studies comprising 1,651 patients showed that the rate of re-operation for proximal and distal aorta was $7.3 \%$ in hemiarch and 3.3\% in extensive total arch replacement, although there was no statistical significance detected between the two groups (RR $=1.45 ; 95 \%$ CI: 0.93-2.28; $\mathrm{P}=0.10, \mathrm{I}^{2}=23 \%$ ) (Figures 7,8 ).

\section{Publication bias}

Following funnel plot analysis, Begg \& Mazumdar rank correlation (Kendall's Tau $=-0.064,1$-tailed $\mathrm{P}$ value $=0.38$ ) and Egger regression test (intercept $=-0.51,1$-tailed $P$ value $=0.20,2$-tailed $\mathrm{P}$ value $=0.41)$ indicated that publication bias was not statistically significant when analyzing in-hospital mortality (Figure 9). Similarly, publication bias was not a significant influencing factor when late events such as aortic re-operation were analyzed. (Begg's test, 1-tailed $\mathrm{P}$ value $=0.30$; Egger's regression, 1 -tailed $\mathrm{P}$ value $=0.12$ ). Trim and Fill analysis indicated no studies were missing.

\section{Discussion}

Acute type A aortic dissection remains a challenging surgical emergency associated with high mortality and morbidity despite advances in the last few decades. According to the International Registry of Acute Aortic Dissection (IRAD) (1), the mortality for surgically treated patients is around $26 \%$. Whether or not, and to what extent the aortic arch should be replaced is an ongoing debate. Current evidence indicates that the dissection process frequently extends through the arch in most patients and that an aortic arch repair is warranted (23). However, there are several factors that influence management of the distal ascending 


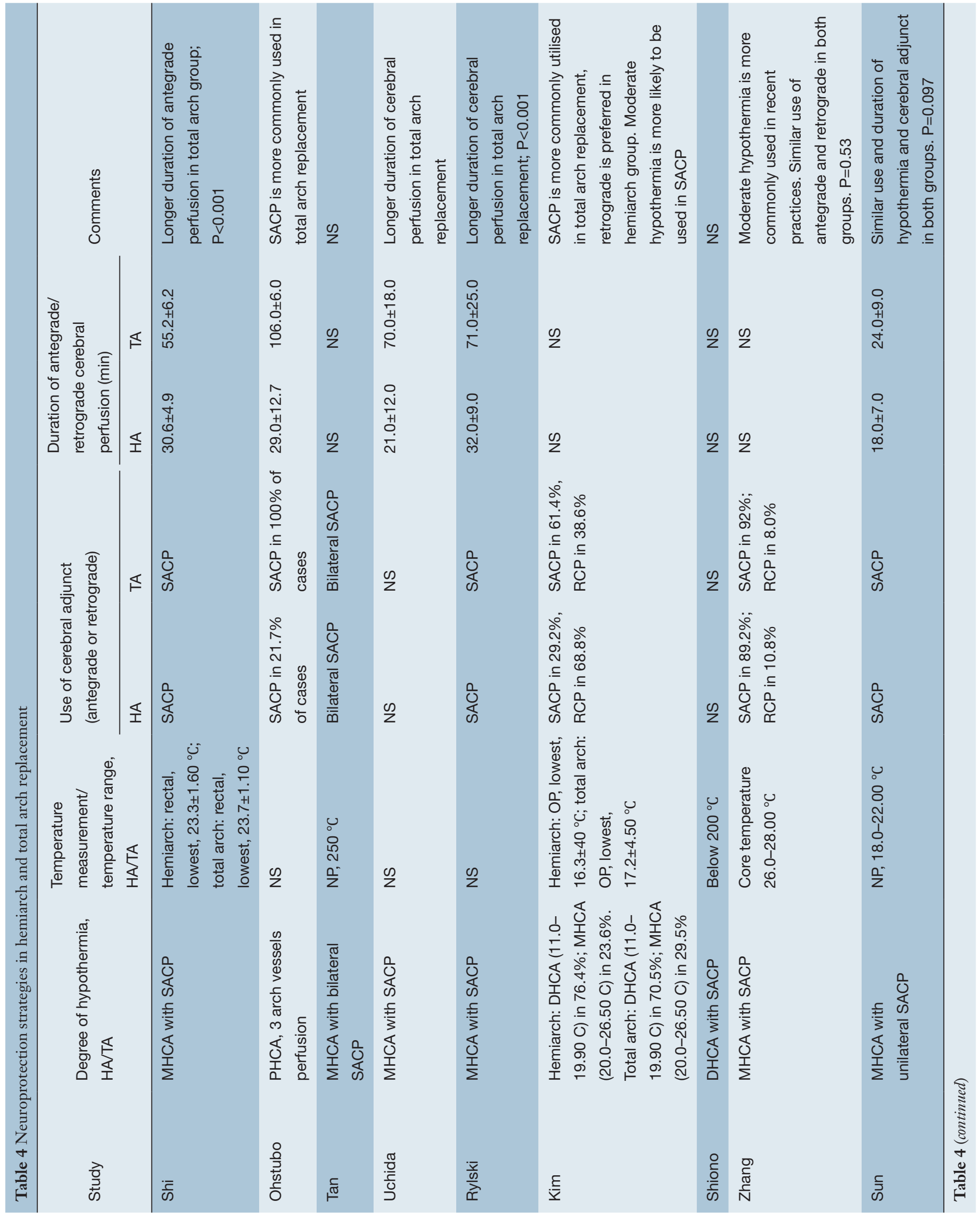




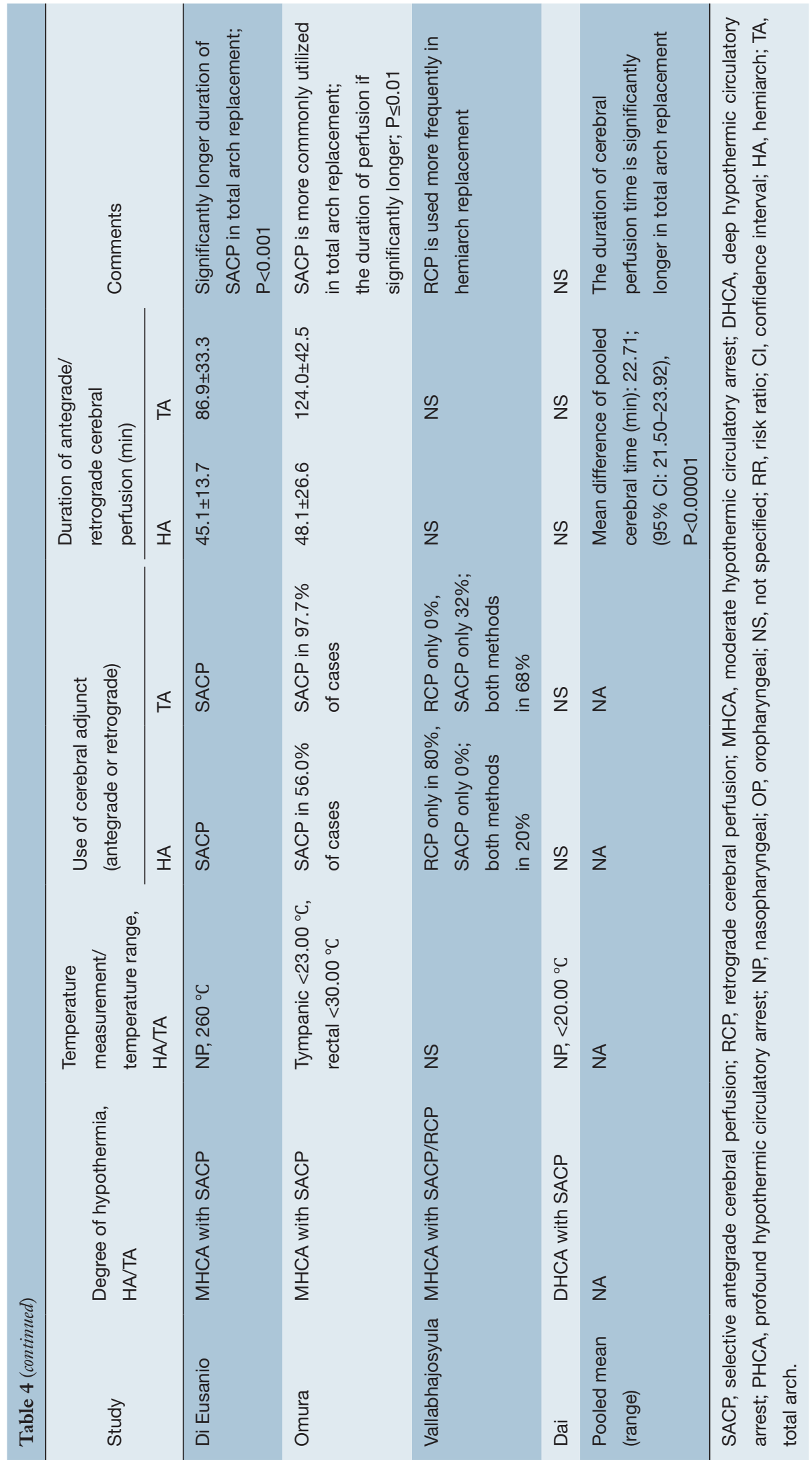




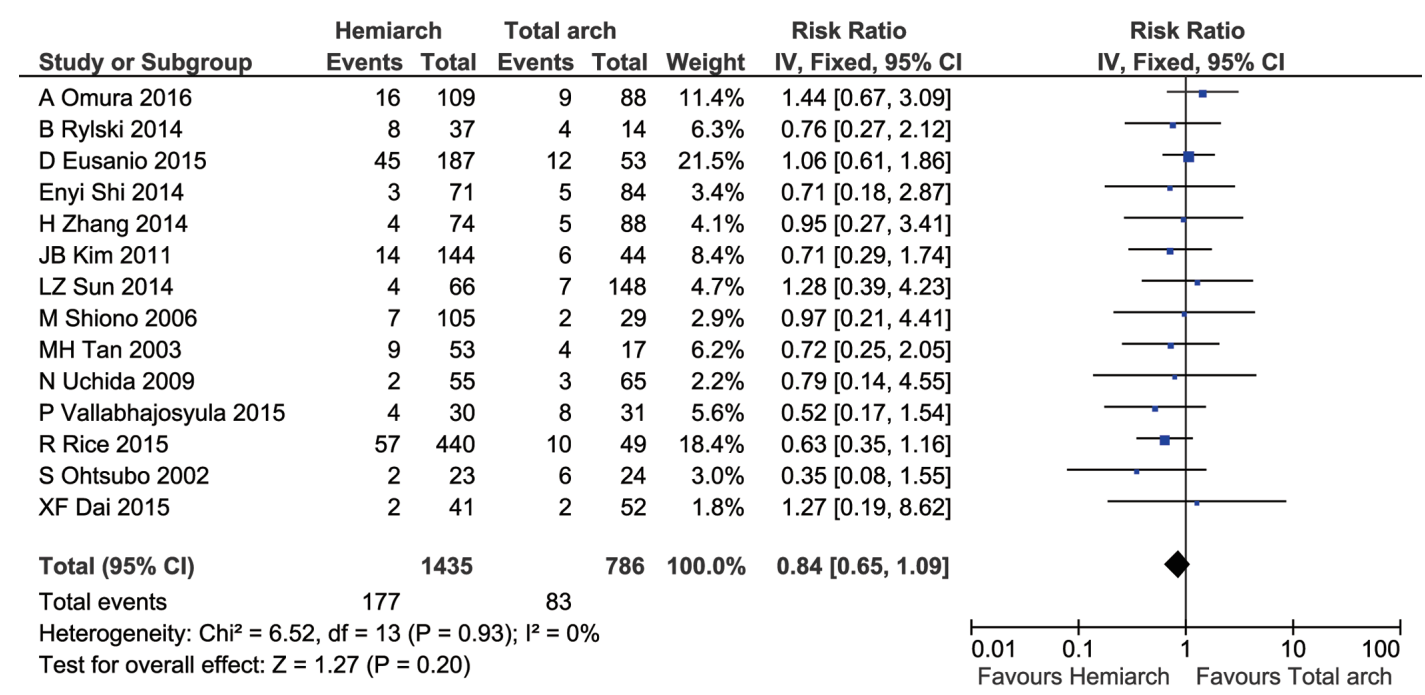

Figure 2 In-hospital mortality. $\mathrm{RR}=0.84$ (95\% CI: $0.65-1.09), \mathrm{P}=0.20, \mathrm{I}^{2}=0 \%$. RR, risk ratio; CI, confidence interval.

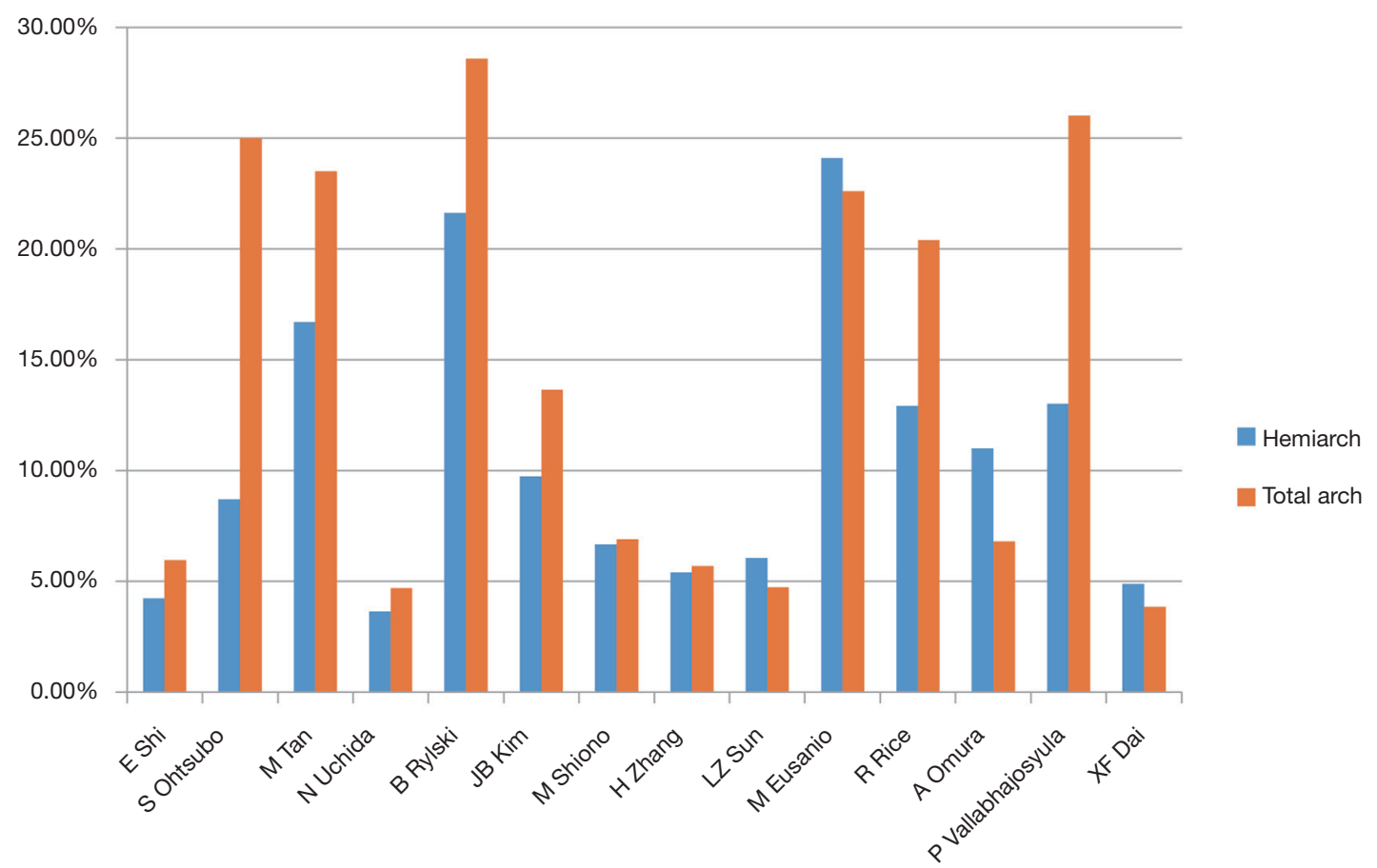

Figure 3 The in-hospital mortality of hemiarch $v$ s. total arch replacement in acute type A dissection. It ranged from 3.60-24.1\% for hemiarch replacement and $3.85-28.57 \%$ for total arch replacement.

aorta and arch and therefore the type of surgical repair $(10,12,16)$. If the tear is localized in the root, ascending or proximal aorta, hemiarch replacement is usually adequate to save a patient life. On the other hand, when the intimal tear is located near the origins of supra-aortic vessels, total aortic arch replacement might be necessary to eliminate the intimal tear (24). The choice of management was based on the surgeon's preference and most aortic centers advocated a conservative tear-oriented strategy, as the primary objective in this high-risk group of patients has to be the survival 


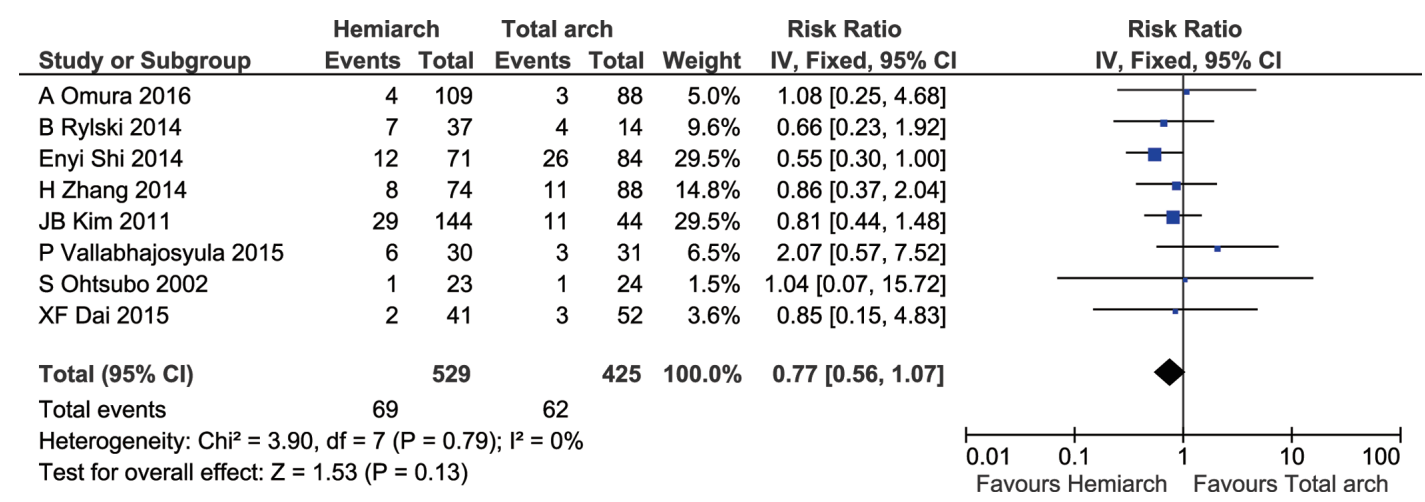

Figure 4 Temporary neurological dysfunction. $\mathrm{RR}=0.77$ (95\% CI: 0.56-1.07), $\mathrm{P}=0.13, \mathrm{I}^{2}=0 \%$. RR, risk ratio; CI, confidence interval.

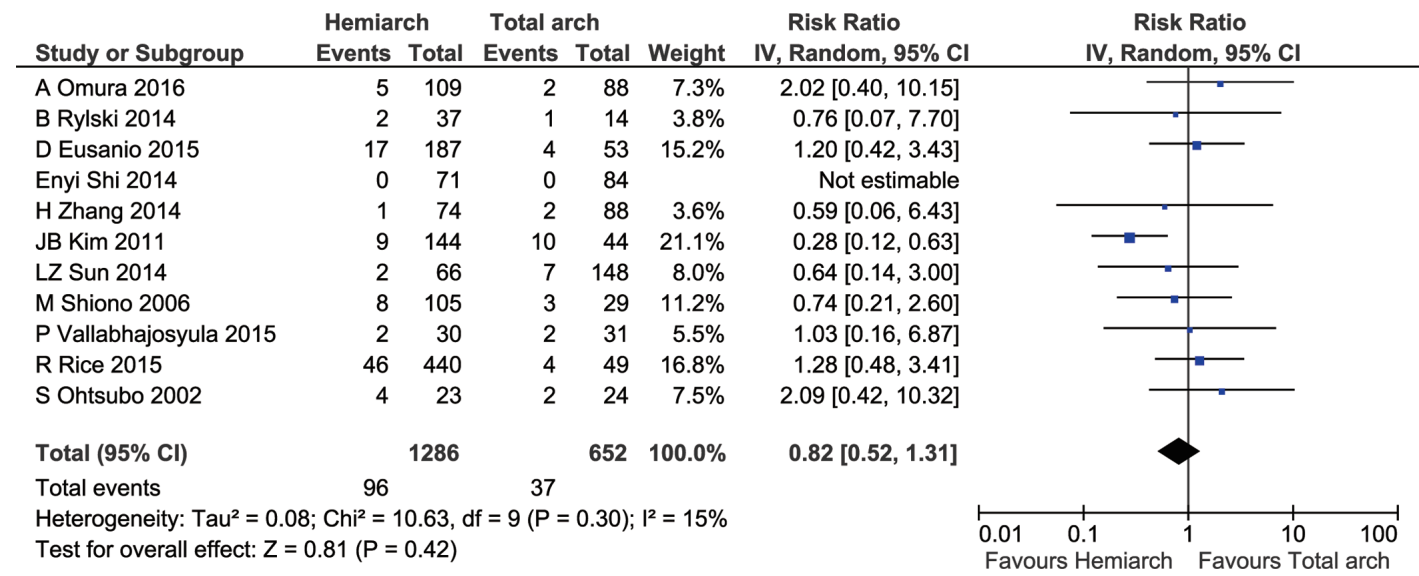

Figure 5 Permanent neurological dysfunction. $\mathrm{RR}=0.82$ (95\% CI: $0.52-1.31$ ), $\mathrm{P}=0.42, \mathrm{I}^{2}=15 \%$. RR, risk ratio; CI, confidence interval.

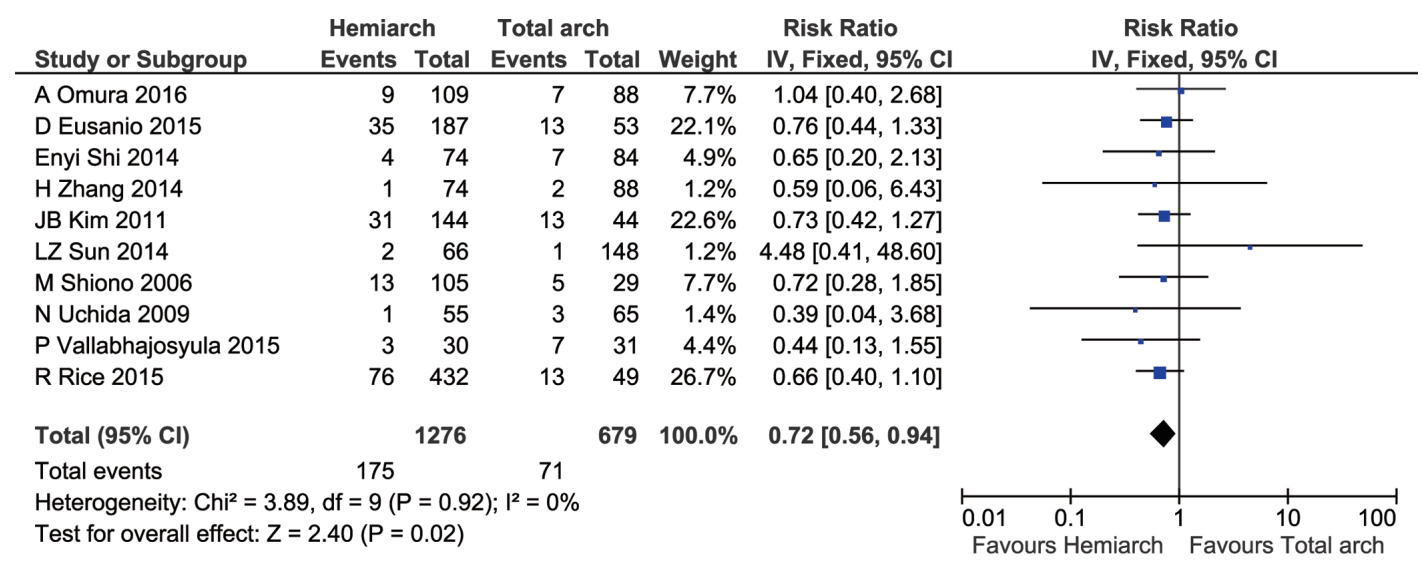

Figure 6 Renal dialysis. $\mathrm{RR}=0.72$ (95\% CI: 0.56-0.94), $\mathrm{P}=0.02, \mathrm{I}^{2}=0 \%$. RR, risk ratio; CI, confidence interval.

of patients and adequate resection of dissected aortic wall $(25,26)$. However, there is a tendency to perform a more extensive total aortic arch replacement with frozen elephant trunk, especially in high-volume aortic centers as the standard treatment with the aim to potentially obliterating the patent false lumen of distal aorta and reducing the risk 


\begin{tabular}{|c|c|c|c|c|c|}
\hline Outcome & No. of patients & No. of studies & RR/WMD $(95 \% \mathrm{Cl})$ & $P$ value & Heterogeneity, $I^{2}$ \\
\hline Mortality & 2,221 & 14 & $0.84(0.65-1.09)$ & 0.20 & 0 \\
\hline Temporary neurological dysfunction & 954 & 8 & $0.77(0.56-1.07)$ & 0.13 & 0 \\
\hline Permanent neurological dysfunction & 1,938 & 11 & $0.82(0.52-1.31)$ & 0.42 & 15 \\
\hline New-onset stroke & 1,458 & 8 & $0.88(0.48-1.62)$ & 0.68 & 0 \\
\hline Renal dialysis & 1,955 & 10 & $0.72(0.56-0.94)$ & 0.02 & 0 \\
\hline Ventilation $>72$ hours & 861 & 7 & $0.77(0.55-1.08)$ & 0.13 & 0 \\
\hline Cardiopulmonary bypass time & 1,966 & 11 & $-47.86(-44.37$ to 51.35$)$ & $<0.00001$ & 97 \\
\hline Cross clamp time & 1,225 & 7 & $-18.68(-5.94$ to 31.43$)$ & $<0.0001$ & 95 \\
\hline Circulatory arrest time & 1,195 & 7 & $-10.73(-3.39$ to 18.07$)$ & $<0.00001$ & 97 \\
\hline $\begin{array}{l}\text { Rate of aortic re-operation (proximal } \\
\text { and distal) }\end{array}$ & 1,651 & 12 & $1.45(0.93-2.28)$ & 0.10 & 23 \\
\hline
\end{tabular}

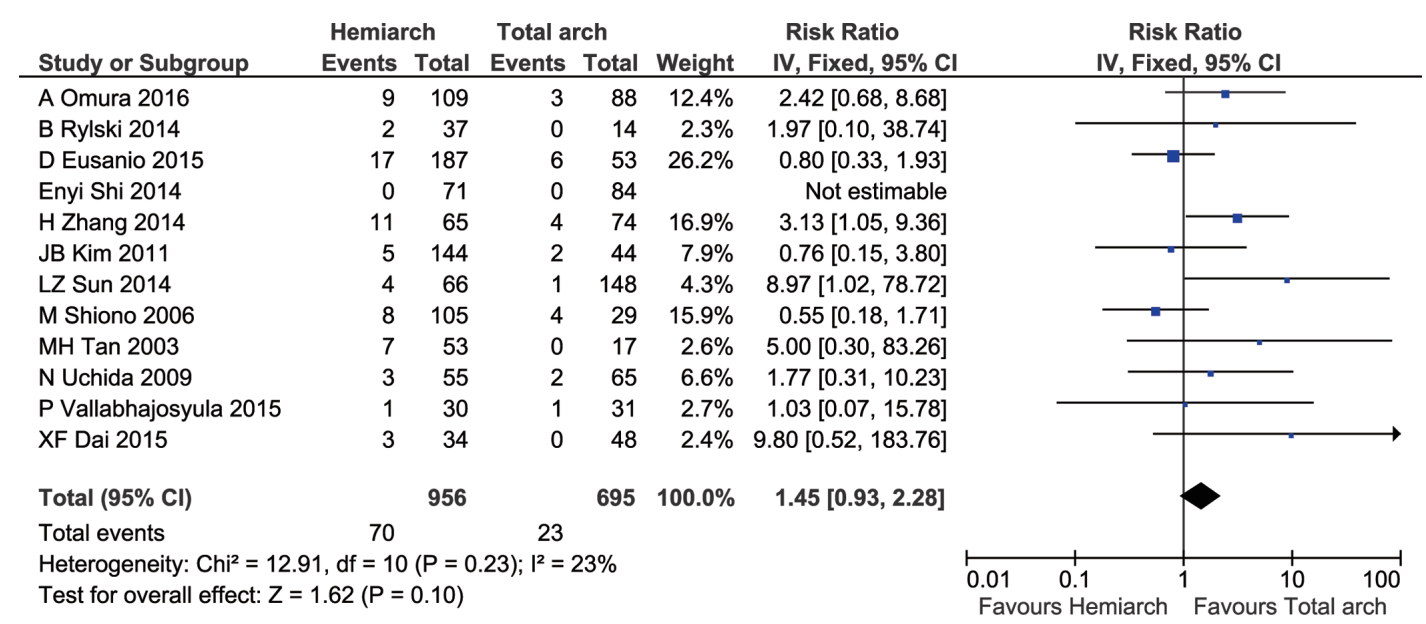

Figure 7 Aortic re-operation. $\mathrm{RR}=1.45$ (95\% CI: 0.93-2.28), $\mathrm{P}=0.10, \mathrm{I}^{2}=23 \%$. RR, risk ratio; CI, confidence interval.

\begin{tabular}{|c|c|c|c|c|c|c|c|c|c|c|}
\hline Study or Subgroup & \multicolumn{2}{|c|}{ Hemiarch } & \multicolumn{2}{|c|}{ Total arch } & O-E & Variance & Weight & $\begin{array}{l}\text { Hazard Ratio } \\
\text { [(O-E) / V], Fixed, 95\% Cl }\end{array}$ & \multicolumn{2}{|c|}{$\begin{array}{c}\text { Hazard Ratio } \\
\text { Exp[(O-E) / V], Fixed, 95\% C }\end{array}$} \\
\hline A Omura 2016 & 9 & 109 & 3 & 88 & -3.34 & 2.94 & $17.1 \%$ & $0.32[0.10,1.01]$ & & \\
\hline B Rylski 2014 & 2 & 37 & 0 & 14 & -0.25 & 0.18 & $1.0 \%$ & $0.25[0.00,25.30]$ & & \\
\hline D Eusanio 2015 & 17 & 187 & 6 & 53 & 1.46 & 3.3 & $19.2 \%$ & $1.56[0.53,4.58]$ & & \\
\hline Enyi Shi 2014 & 0 & 71 & 0 & 84 & -0.05 & 2.71 & $15.7 \%$ & $0.98[0.30,3.23]$ & & \\
\hline JB Kim 2011 & 5 & 144 & 2 & 44 & 0.95 & 1.77 & $10.3 \%$ & $1.71[0.39,7.46]$ & & \\
\hline M Shiono 2006 & 8 & 105 & 4 & 29 & -0.5 & 1.97 & $11.4 \%$ & $0.78[0.19,3.13]$ & & \\
\hline MH Tan 2003 & 7 & 53 & 0 & 17 & 0.06 & 1.23 & $7.1 \%$ & $1.05[0.18,6.15]$ & & \\
\hline N Uchida 2009 & 3 & 55 & 2 & 65 & -3.65 & 3.12 & $18.1 \%$ & $0.31[0.10,0.94]$ & & \\
\hline Total $(95 \% \mathrm{Cl})$ & & 761 & & 394 & & & $100.0 \%$ & $0.73[0.46,1.18]$ & & \\
\hline Total events & 51 & & 17 & & & & & & & \\
\hline $\begin{array}{l}\text { Heterogeneity: } \mathrm{Chi}^{2}= \\
\text { Test for overall effect }\end{array}$ & $\begin{array}{l}05, \mathrm{df}=7 \\
=1.28(\mathrm{~F}\end{array}$ & $\begin{array}{l}7(P=0 \\
P=0.2\end{array}$ & $\begin{array}{l}\text {.33); } 1^{2}=1 \\
0)\end{array}$ & & & & & & $\begin{array}{lll}0.01 & 0.1 & 1 \\
\text { Favours Hemiarch }\end{array}$ & $1 \frac{10}{\text { Favours Total }}$ \\
\hline
\end{tabular}

Figure 8 Pooled HR for freedom of re-operation. Overall HR =0.73 (95\% CI: 0.46-1.18), P=0.20, $\mathrm{I}^{2}=13 \%$. HR, hazard ratio; CI, confidence interval. 


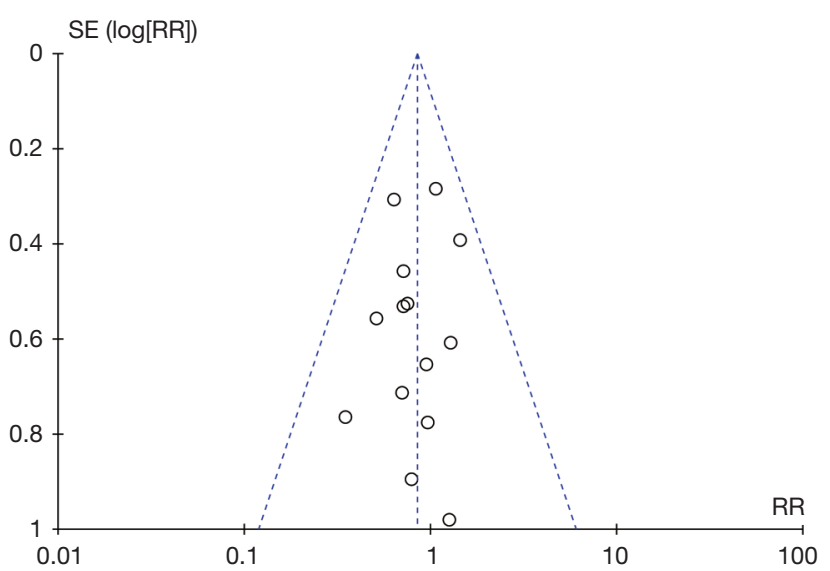

Figure 9 Funnel plot in-hospital mortality. Begg \& Mazumdar rank correlation (Kendall's Tau $=-0.064,1$-tailed $\mathrm{P}$ value $=0.38$ ) and Egger regression test (intercept $=-0.51,1$-tailed $\mathrm{P}$ value $=0.20$, 2 -tailed $\mathrm{P}$ value $=0.41$ ) indicated that publication bias was not statistically significant when analyzing post-operative mortality.

of aortic dilatation and late aortic re-intervention $(4,27,28)$. Other factors that may push a surgeon to perform a total arch replacement are age, syndromic disease, aneurysm or extensive aortic arch destruction. There are encouraging reports for this technique but the complicated procedure of total arch replacement still posed a great challenge and steep learning curve to many cardiac surgeons. When a long-term stent graft is inserted, the risk of paraplegia and spinal cord injury must be considered due to extensive sacrifice of spinal arteries impairing collateral blood flow to the spinal cord, combined with inadequate protection during the operation (14). The longer cardiopulmonary bypass and cardiac arrest time, aortic cross-clamping time and cerebral perfusion time might inevitably be associated with post-operative cardiac and cerebral injury and organ dysfunction $(25,29-32)$. In some cases, extending the initial surgery to total arch replacement might not be able to eliminate the entire dissection in the downstream aorta, e.g., at the level of coeliac trunk and iliac arteries (14).

Our meta-analysis is contemporary to a similar study published recently (33). However, the previous metaanalysis included studies only up to September 2014, indicating the potential weaknesses of the outdated search strategy. Also, the review included the data from a registry study (GERAADA) which accounted for the majority of their early mortality pooled analysis outcome (54.4\%) in the absence of long term end-points to justify the necessity of possible aortic re-intervention for patients treated for acute type A aortic dissection by either hemiarch or total arch replacement. As acknowledged by the authors, fewer than ten studies were included in their initial analysis which might limit the convincingness of their conclusion and the Newcastle-Ottawa Score (NOS) for the GERAADA study was six. We have excluded studies with an NOS score of less than seven due to risk of substantial bias. Our up to date search strategy resulted in six more key and balanced studies $(12,18-22)$ comparing conservative versus extensive arch replacement, resulting in comparison of 1,435 conservative hemiarch replacement and 786 extensive total arch replacement as opposed to 1,236 proximal and 646 extensive replacement in the earlier published review. The estimates provided by our review for long-term follow-up data are more robust due to inclusion of more follow-up studies and time-to-event analysis of freedom from aortic re-operation, in addition to initial published studies. We have included ancillary outcomes such as temporary and permanent neurological dysfunction, ventilation beyond 72 hours, re-operation for bleeding, renal dialysis, longterm survival data, mortality data for late re-operation and pooled hazard ratio for freedom of aortic re-operation as part of our review. To overcome the baseline differences between the two study groups, we have described a novel method of reporting the neuroprotective strategies and the pooled mean of pre-operative parameters with statistical significance. These were not addressed in the previous meta-analysis.

To systematically evaluate the operative outcomes of conservative hemiarch replacement versus a more extensive total arch replacement, the present meta-analysis identified all eligible comparative studies in the existing literature. Data from the meta-analysis suggested that hemiarch replacement was associated with a lower risk of renal dialysis post-operatively. There was no significant difference in terms of mortality between the two groups despite a higher risk profile for the hemiarch group. Operative times such as cardiopulmonary bypass, aortic cross clamp and circulatory arrest times were significantly longer in total arch replacement. There was no significant difference between the two operative approaches in terms of long term survival and freedom from aortic reoperation during follow up. More importantly, the type of arch replacement and complete thrombosis of false lumen did not correlate with aortic re-operation both proximally and distally, and the mortality associated with re-operation for aortic dilatation is low. 
Our study showed that arch replacement alone does not necessarily compromise short-term survival, and that hemiarch replacement is associated with favorable early morbidity which could be in part attributed to shorter operative times and less aggressive initial surgery. In a large study by Estrera and associates (19), 440 proximal arch repairs (hemiarch) were compared with 49 total arch replacements. The 30 -day mortality was $20.4 \%$ for total arch replacement and $12.9 \%$ for hemiarch replacement, although the results did not reach statistical significance $(\mathrm{P}=0.150)$. Sun et al. (4) matched 148 patients who underwent total arch replacement with stented elephant trunk over a 42-month period to conservative arch repair. They demonstrated no significant difference in mortality between the two groups ( $4.7 \%$ vs. $6.1 \%$ respectively; $\mathrm{P}=0.741)$. Shi and Zhang et al. $(4,17)$ included patients without an intimal tear in the arch, and excluding these studies from the pooled analysis did not yield any differences in terms of mortality $(\mathrm{P}=0.21)$. Similar observation was also reported in a registry study (GERAADA) where the mortality rate is slightly lower in the hemiarch group (6). Despite our findings that total arch replacement was not associated with significantly higher mortality compared to the more conservative approach, the results may not be seen in low volume centers where most patients with acute dissection undergo surgery (34). More importantly, the higher incidence of pre-operative cardiogenic shock and tamponade in the hemiarch cohort $(\mathrm{P}=0.0003)$ may theoretically increase the mortality, resulting in comparable pooled mortality results between the two groups. Thus, in patients presenting with cardiogenic shock or tamponade, a more conservative approach may be recommended. However, it remained unclear whether the pre-operative status of patients or the intra-operative skills of surgeons was the primary factor that influenced the mortality observed between the two groups. A recent study on a national database by Chikwe et al. (35) demonstrated that patients with acute dissections operated on by lower-volume surgeons have approximately double the mortality-adjusted risk compared to patients operated by higher-volume surgeons. Thus, in centers where total arch replacement with frozen elephant trunk is not routinely performed, such a strategy might not be appropriate, especially in the emergency setting.

Preventing ischemic injury to the central nervous system in aortic arch surgery has been a substantial challenge and this might influence the operative strategy chosen for aortic arch replacement (36-38). The present meta-analysis did not identify any statistical significant differences in new-onset stroke and risk of paraplegia between the two groups. The incidence of paraplegia and spinal cord injury was reported in six studies with no significant differences between the two groups. In a large series of 214 patients presenting with acute type A dissection, Sun et al. (4) reported two cases of paraplegia $(1.4 \%)$ in the total arch replacement with frozen elephant trunk group, although it did not reach statistical difference $(\mathrm{P}=1.0)$. Similarly, Kim et al. (15) reported two cases of paraplegia post-operatively, one in each group $(2.3 \%$ and $0.7 \%$ respectively). These data support the premise that neurological events are a result of multi-factorial events, and that effective cerebral protection, rather than the extent of graft replacement, independently predicts neurological complications. Moreover, given the operative complexity, it is not surprising that that selective antegrade cerebral perfusion (SACP) is more commonly used in total arch replacement with a longer duration of perfusion time. The data is tabulated in Table 4. To some extent, this alternative neuroprotection strategy may account for the similar rate of temporary and permanent neurological deficits observed in both groups. In general, the current trend of temperature and neuroprotection strategy involved moderate hypothermic circulatory arrest (MHCA) with SACP for aortic arch replacement. Whether it is best done using unilateral/bilateral perfusion or axillary/femoral cannulation is still a matter of debate. In keeping with other studies, the longer cardiopulmonary bypass, aortic cross clamp, and cardiac arrest time with total arch replacement might be directly related to cardiac, cerebral and organ injuries $(30,31)$. In this meta-analysis, the incidence of postoperative renal dialysis was significantly higher in total arch replacement. This might be directly related to prolonged bypass and visceral ischaemic time. Estrera and associates at Houston reported a higher need of post-operative dialysis in the total arch cohort (27.1\%) compared to the proximal arch cohort $(17.6 \%)$ and that a pre-operative eGFR of less than $60 \mathrm{~mL} / \mathrm{min} / 1.73 \mathrm{~m}^{2}$ is independently associated with increased mortality (19) (HR 1.48, $\mathrm{P}=0.027$ ). In addition, Kim et al. (15) also reported a higher incidence of renal dialysis post operatively, $29.5 \%$ in total arch and $21.5 \%$ in hemiarch replacement in a series of 188 patients, although this did not reach statistical significance $(\mathrm{P}=0.27)$. Prolonged cardiopulmonary bypass will likely have an impact, especially on renal hemodynamics, and these potentially modifiable changes can be associated with regional renal injury post-operatively $(39,40)$.

Comparing a cohort of 197 consecutive patients, Omura 
et al. (20) found comparable 5- and 10-year survivals after discharge from hospital between the two groups, $88.6 \% \pm 4.2 \%$ and $83.6 \% \pm 4.4 \%$ for total arch replacement and $83.8 \% \pm 4.4 \%$ and $76.5 \% \pm 5.8 \%$, in the conservative arch group respectively, $\mathrm{P}=0.54$. This compares favorably with eight other studies included. Kim et al. (15) reported slightly better survival in the hemiarch group at five years, $83.2 \% \pm 3.3 \%$ vs. $65.8 \% \pm 8.3 \%, \mathrm{P}=0.013$ after adjusting for multivariate variables. On the contrary, Uchida et al. (13) (95.3\% vs. 69\%, $\mathrm{P}=0.03$ ) and Rylski et al. (14) ( $79 \%$ vs. $64 \%, \mathrm{P}=0.0062$ ) reported slightly greater survival for total arch replacement at five years but this may be explained by lower risk profile. In terms of freedom from aortic reintervention, multiple cohort studies have shown equivalent results between hemiarch and total arch replacement. In a recent study by Omura et al. (20), with a follow up period of up to ten years, the freedom from elective aortic reoperation was $91.7 \%$ for total arch and $83.3 \%$ for conservative arch replacement, with no significant difference between the two groups $(\mathrm{P}=0.20)$. The survival data from various centres also showed that elective aortic arch repair can be performed in future re-operation with low and acceptable mortality risk and thus can be deferred, as shown in ten studies. Data on long term survival and freedom from aortic reoperation is shown in Table 6.

The behavior of the false lumen following surgery was examined with computed tomography (CT) imaging in seven studies $(11,15-17,20,23,24)$. Omura et al. (20) monitored 128 (74.4\%) hospital survivors with postoperative CT performed twice, at least 6 months apart, to determine the aortic growth rate. During follow up, the diameter of aorta at the level of the distal arch and mid-descending aorta was $36.2 \pm 4.9$ and $32.1 \pm 4.0 \mathrm{~mm}$ respectively. The diameter of the distal arch exceeded $50 \mathrm{~mm}$ in three $(3.4 \%)$ and eight patients $(7.3 \%)$ who underwent total arch replacement and conservative arch management. In three other studies, the distal aorta was dilated $>55 \mathrm{~mm}$ in $16.9 \%, 5.6 \%$ and $6.9 \%$ in the hemiarch group and 5.4\%, $4.7 \%$ and $4.5 \%$ in the total arch replacement group, although no significant differences were detected $(\mathrm{P}=0.57)$. In terms of complete thrombosis of the false lumen, Zhang et al. (17) reported 100\% thrombosis at the transverse arch and proximal descending aorta and $45.1 \%$ at diaphragmatic level during 6-12 months of follow up. On the contrary, the formation of complete thrombosis was only seen in $38.4 \%, 24.6 \%$ and $20.3 \%$ at the level of the transverse arch, proximal descending aorta and diaphragm in the hemiarch group. Total arch replacement with a stent may promote false lumen thrombosis, but in two other studies where primary tear resection was accomplished in $92 \%$ and $97.6 \%$ of patients, no significant differences were detected in the patency of the false lumen during follow up $(11,16)$. This suggests that the incidence of a patent false lumen might not be influenced by the extent of resection but rather, successful resection of the primary tear. Moreover, since the false lumen can remain patent at the diaphragmatic level despite total arch replacement with concomitant stenting, this highlights the importance of continuous and frequent CT monitoring post-operatively, regardless of the surgical approach.

\section{Limitations}

The present study was limited by several factors. Firstly, this was a retrospective analysis of observational studies with inherent drawbacks. Unmeasured confounders, as well as publication and detection bias could exist, especially with the inclusion of high-volume centers performing total arch replacement who published acceptable outcomes. Hence, the results might not be representative of all institutions as discussed earlier. Without appropriate randomization, the results may reflect the patient's characteristics and surgeon's level of experience rather than the surgical approach. In terms of time-related outcomes, although they were statistically significant, there remained significant heterogeneity in the studies, which may in part reflect the varying degree of complexity involved in aortic arch replacement for type A dissection between individual institutions. Finally, treatment bias was evident in the studies, as total arch replacement was more commonly performed in younger patients, those with Marfan syndrome. This may reflect that each surgeon has different experience and comfort levels for the treatment of type A dissection, and it may be difficult to account for this preference bias.

\section{Conclusions}

Within the context of publication bias by high volume aortic centres and non-randomized data sets, there was no difference in mortality between the two groups. This analysis serves to demonstrate that for those center performing sufficient total aortic arch procedures to allow for publication, excellent and equivalent outcomes are 
Table 6 Studies reporting intermediate and long term outcomes

\begin{tabular}{|c|c|c|c|c|}
\hline Author, year & Institution & Survival ( HA vs. TA) ${ }^{\star *}$ & $\begin{array}{l}\text { Freedom from aortic } \\
\text { reoperation }(\mathrm{HA} \text { vs. } \mathrm{TA})^{\star *}\end{array}$ & $\begin{array}{l}\text { Mortality from aortic } \\
\text { reoperation ( HA vs. TA) }\end{array}$ \\
\hline Shi et al., 2014 & $\begin{array}{l}\text { Shenyang, } \\
\text { China }\end{array}$ & $\begin{array}{l}88.3 \% \text { for whole cohort at } 5 \text { years, } \\
P=0.56\end{array}$ & $\begin{array}{l}88 \% \text { vs. } 91.3 \% \text { at } 5 \text { years, } \mathrm{P}=0.62 ; \\
\text { pooled } \mathrm{HR}=0.98(95 \% \mathrm{Cl}: 0.30-3.23)\end{array}$ & $\begin{array}{l}\text { No death in either } \\
\text { groups }\end{array}$ \\
\hline $\begin{array}{l}\text { Ohtsubo et al., } \\
2002\end{array}$ & Saga, Japan & $\begin{array}{l}91.3 \% \pm 5.9 \% \text { vs. } 44.4 \% \pm 14.3 \% \text { at } \\
5 \text { years, } P=0.018\end{array}$ & $\begin{array}{l}93.8 \% \pm 6.3 \% \text { vs. } 100 \% \pm 0 \% \text { at } \\
5 \text { years, } P=0.86 ; H R=N A\end{array}$ & NS \\
\hline $\begin{array}{l}\text { Uchida et al., } \\
2009\end{array}$ & $\begin{array}{l}\text { Hiroshima, } \\
\text { Japan }\end{array}$ & $69 \%$ vs. $95.3 \%$ at 5 years, $P=0.03$ & $\begin{array}{l}70.3 \% \text { vs. } 88.6 \% \text { at } 5 \text { years, } P=0.02 \\
\text { pooled } \mathrm{HR}=0.31 \text { ( } 95 \% \mathrm{Cl}: 0.10-0.94)\end{array}$ & None reported \\
\hline $\begin{array}{l}\text { Rylski et al., } \\
2014\end{array}$ & $\begin{array}{l}\text { Freiburg, } \\
\text { Germany }\end{array}$ & $64 \%$ vs. $79 \%$ at 5 years, $P=0.0062$ & $\begin{array}{l}97 \% \pm 3 \% \text { vs. } 100 \% \text { at } 5 \text { years, } \\
P=0.440 ; \text { pooled } \mathrm{HR}=0.25(95 \% \mathrm{Cl} \text { : } \\
0.00-25.30)\end{array}$ & $\begin{array}{l}1 \text { died in the hemiarch } \\
\text { group }\end{array}$ \\
\hline $\begin{array}{l}\text { Shiono et al., } \\
2006\end{array}$ & Tokyo, Japan & $\begin{array}{l}63.5 \% \text { vs. } 80.8 \% \text { at } 10 \text { years, } \\
P=0.72\end{array}$ & $\begin{array}{l}60.9 \% \text { vs. } 76.6 \% \text { at } 10 \text { years, } \mathrm{P}=0.48 \\
\text { pooled } \mathrm{HR}=0.78(95 \% \mathrm{Cl}: 0.19-3.13)\end{array}$ & $\begin{array}{l}\text { No death reported in } \\
\text { either groups }\end{array}$ \\
\hline $\begin{array}{l}\text { Zhang et al., } \\
2014\end{array}$ & Shanghai, China & $80.5 \%$ vs. $87.7 \%$ at 8 years, $P=0.11$ & NS & 1 died in hemiarch group \\
\hline Sun et al., 2014 & Beijing, China & No significant differences, $P=0.943$ & NS & $\begin{array}{l}\text { No death reported in } \\
\text { either groups }\end{array}$ \\
\hline $\begin{array}{l}\text { Di Eusanio et al., } \\
2015\end{array}$ & Bologna, Italy & $\begin{array}{l}57.2 \% \pm 4.2 \% \text { vs. } 52.1 \% \pm 9.9 \% \text { at } \\
7 \text { years, } P=0.89\end{array}$ & $\begin{array}{l}85.4 \% \pm 3.9 \% \text { vs. } 71.6 \% \pm 13.2 \% \text { at } \\
7 \text { years, } P=0.29 \text {; pooled } \mathrm{HR}=1.56 \\
(95 \% \mathrm{Cl}: 0.53-4.58)\end{array}$ & $\begin{array}{l}\text { No death reported in } \\
\text { either groups }\end{array}$ \\
\hline $\begin{array}{l}\text { Vallabhajosyula } \\
\text { et al., } 2015\end{array}$ & $\begin{array}{l}\text { Philadelphia, } \\
\text { USA }\end{array}$ & $\begin{array}{l}73 \% \pm 8.3 \% \text { vs. } 67 \% \pm 8.6 \% \text { at } \\
5 \text { years, } P=0.56\end{array}$ & NS & $\begin{array}{l}\text { No death in either } \\
\text { groups }\end{array}$ \\
\hline Dai et al., 2015 & Fujian, China & $83.3 \%$ vs. $94.1 \%$ at 5 years, $\mathrm{P}<0.05$ & NS & $\begin{array}{l}1 \text { died in hemiarch group } \\
\text { due to descending } \\
\text { aortic dilatation }\end{array}$ \\
\hline $\begin{array}{l}\text { Overall pooled } \\
\mathrm{HR}(95 \% \mathrm{Cl})\end{array}$ & NA & NA & $\begin{array}{l}0.73 \text { (95\% Cl: } 0.46-1.18) ; P=0.20 \\
I^{2}=13 \%\end{array}$ & NA \\
\hline
\end{tabular}

**, actuarial survival data and freedom from aortic reoperation were prepared using Kaplan-Meier cumulative survival method. Data were compared using the log-rank test. NS, not specified; HR, hazard ratio; Cl, confidence interval; HA, hemiarch; TA, total arch. 
achievable. Conclusions on differences in longer term outcome data are required. We do not however advocate total arch as a primary approach by all centers and surgeons irrespective of patient characteristics, but rather, a tailored approach based on surgeon and center experience and patient presentation.

\section{Acknowledgements}

None.

\section{Footnote}

Conflicts of Interest: The authors have no conflicts of interest to declare.

\section{References}

1. Hagan PG, Nienaber CA, Isselbacher EM, et al. The International Registry of Acute Aortic Dissection (IRAD) New insights into an old disease. JAMA 2000;283:897-903.

2. Malaisrie SC, Duncan BF, Mehta CK, et al. The addition of hemiarch replacement to aortic root surgery does not affect safety. J Thorac Cardiovasc Surg 2015;150:118-24.e2.

3. Bonser RS, Ranasinghe AM, Loubani M, et al. Evidence, Lack of Evidence, Controversy, and Debate in the Provision and Performance of the Surgery of Acute Type A Aortic Dissection. J Am Coll Cardiol 2011;58:2455-74.

4. Sun L, Qi R, Zhu J, et al. Total arch replacement combined with stented elephant trunk implantation: a new "standard" therapy for type a dissection involving repair of the aortic arch? Circulation 2011;123:971-8.

5. Sun LZ, Qi RD, Chang Q, et al. Is total arch replacement combined with stented elephant trunk implantation justified for patients with chronic Stanford type A aortic dissection? J Thorac Cardiovasc Surg 2009;138:892-6.

6. Weigang E, Conzelmann LO, Kallenbach K, et al. German registry for acute aortic dissection type A (GERAADA)-lessons learned from the registry. Thorac Cardiovasc Surg 2010;58:154-8.

7. Wells GA, Shea B, O'Connell D, et al. The NewcastleOttawa Scale (NOS) for assessing the quality of nonrandomised studies in meta-analysis. 2013. Available online: http://www.ohri.ca/programs/clinical_ epidemiology/oxford.asp

8. Tierney JF, Stewart LA, Ghersi D, et al. Practical methods for incorporating summary time-to-event data into metaanalysis. Trials 2007;8:16.
9. Stroup DF, Berlin JA, Morton SC, et al. Meta-analysis of observational studies in epidemiology: a proposal for reporting. Meta-analysis Of Observational Studies in Epidemiology (MOOSE) group. JAMA 2000;283:2008-12.

10. Shi E, Gu T, Yu Y, et al. Early and midterm outcomes of hemiarch replacement combined with stented elephant trunk in the management of acute DeBakey type I aortic dissection: comparison with total arch replacement. J Thorac Cardiovasc Surg 2014;148:2125-31.

11. Ohtsubo S, Itoh T, Takarabe K, et al. Surgical results of hemiarch replacement for acute type A dissection. Ann Thorac Surg 2002;74:S1853-6.

12. Tan ME, Dossche KM, Morshuis WJ, et al. Is Extended Arch Replacement for Acute Type A Aortic Dissection an Additional Risk Factors for Mortality? Ann Thorac Surg 2003;76:1209-14.

13. Uchida N, Shibamura H, Katayama A, et al. Operative Strategy for Acute Type A Aortic Dissection: Ascending Aortic or Hemiarch Versus Total Arch Replacement With Frozen Elephant Trunk. Ann Thorac Surg 2009;87:773-7.

14. Rylski B, Beyersdorf F, Kari FA, et al. Acute type A aortic dissection extending beyond ascending aorta: Limited or extensive distal repair. J Thorac Cardiovasc Surg 2014;148:949-54; discussion 54.

15. Kim JB, Chung CH, Moon DH, et al. Total arch repair versus hemiarch repair in the management of acute DeBakey type I aortic dissection. Eur J Cardiothorac Surg 2011;40:881-7.

16. Shiono M, Hata M, Sezai A, et al. Validity of a limited ascending and hemiarch replacement for acute type A aortic dissection. Ann Thorac Surg 2006;82:1665-9.

17. Zhang H, Lang XL, Lu FL, et al. Acute type A dissection without intimal tear in arch: Proximal or extensive repair? J Thorac Cardiovasc Surg 2014;147:1251-5.

18. Di Eusanio M, Berretta P, Cefarelli M, et al. Total Arch Replacement Versus More Conservative Management in Type A Acute Aortic Dissection. Ann Thorac Surg 2015;100:88-94.

19. Rice RD, Sandhu HK, Leake SS, et al. Is Total Arch Replacement Associated With Worse Outcomes During Repair of Acute Type A Aortic Dissection? Ann Thorac Surg 2015;100:2159-65.

20. Omura A, Miyahara S, Yamanaka K, et al. Early and late outcomes of repaired acute DeBakey type I aortic dissection after graft replacement. J Thorac Cardiovasc Surg 2016;151:341-8.

21. Vallabhajosyula P, Gottret JP, Robb JD, et al. Hemiarch replacement with concomitant antegrade stent grafting of 
the descending thoracic aorta versus total arch replacement for treatment of acute DeBakey I aortic dissection with arch teardagger. Eur J Cardiothorac Surg 2016;49:1256-61.

22. Dai XF, Chen LW, Wu XJ, et al. Total Aortic Arch Reconstruction With Triple-Branched Stent Graft or Hemiarch Replacement for Acute Debakey Type I Aortic Dissection: Five-Years Experience With 93 Patients. J Card Surg 2015;30:749-55.

23. Weigang E, Nienaber CA, Rehders TC, et al. Management of Patients With Aortic Dissection. Dtsch Arztebl Int 2008;105:639-45.

24. Uchida N, Katayama A, Tamura K, et al. Frozen elephant trunk technique and partial remodeling for acute type A aortic dissection. Eur J Cardiothorac Surg 2011;40:1066-71.

25. Al-Sarraf N, Thalib L, Hughes A, et al. Cross-clamp time is an independent predictor of mortality and morbidity in low- and high-risk cardiac patients. Int J Surg 2011;9:104-9.

26. Westaby S, Saito S, Katsumata T. Acute type A dissection: conservative methods provide consistently low mortality. Ann Thorac Surg 2002;73:707-13.

27. Di Bartolomeo R, Pantaleo A, Berretta P, et al. Frozen elephant trunk surgery in acute aortic dissection. J Thorac Cardiovasc Surg 2015;149:S105-9.

28. Katayama A, Uchida N, Katayama K, et al. The frozen elephant trunk technique for acute type A aortic dissection: results from 15 years of experiencedagger. Eur J Cardiothorac Surg 2015;47:355-60; discussion 60.

29. Taylor KM. Central nervous system effects of cardiopulmonary bypass. Ann Thorac Surg 1998;66:S20-4; discussion S25-8.

30. Venn GE, Patel RL, Chambers DJ. Cardiopulmonary bypass: perioperative cerebral blood flow and postoperative cognitive deficit. Ann Thorac Surg 1995;59:1331-5.

31. Fearn SJ, Pole R, Wesnes K, et al. Cerebral injury during cardiopulmonary bypass: emboli impair memory. J Thorac Cardiovasc Surg 2001;121:1150-60.

32. Nissinen J, Biancari F, Wistbacka JO, et al. Safe time limits of aortic cross-clamping and cardiopulmonary bypass in adult cardiac surgery. Perfusion 2009;24:297-305.

33. Yan Y, Xu L, Zhang H, et al. Proximal aortic repair versus extensive aortic repair in the treatment of acute type A aortic dissection: a meta-analysis. Eur J Cardiothorac Surg 2016;49:1392-401.

34. Lenos A, Bougioukakis P, Irimie V, et al. Impact of surgical experience on outcome in surgery of acute type A aortic dissection. Eur J Cardiothorac Surg 2015;48:491-6.

35. Chikwe J, Cavallaro P, Itagaki S, et al. National Outcomes in Acute Aortic Dissection: Influence of Surgeon and Institutional Volume on Operative Mortality. Ann Thorac Surg 2013;95:1563-9.

36. Tsukube T, Hayashi T, Kawahira T, et al. Neurological outcomes after immediate aortic repair for acute type A aortic dissection complicated by coma. Circulation 2011;124:S163-7.

37. Sun X, Lindsay J, Monsein LH, et al. Silent Brain Injury After Cardiac Surgery: A Review. J Am Coll Cardiol 2012;60:791-7.

38. Wan IYP, Angelini GD, Bryan AJ, et al. Prevention of spinal cord ischaemia during descending thoracic and thoracoabdominal aortic surgery. Eur J Cardiothorac Surg 2001;19:203-13.

39. Rosner MH, Okusa MD. Acute kidney injury associated with cardiac surgery. Clin J Am Soc Nephrol 2006;1:19-32.

40. Boldt J, Brenner T, Lehmann A, et al. Is kidney function altered by the duration of cardiopulmonary bypass? Ann Thorac Surg 2003;75:906-12.
Cite this article as: Poon SS, Theologou T, Harrington D, Kuduvalli M, Oo A, Field M. Hemiarch versus total aortic arch replacement in acute type A dissection: a systematic review and meta-analysis. Ann Cardiothorac Surg 2016;5(3):156-173. doi: 10.21037/acs.2016.05.06 


\section{Newcastle-Ottawa quality assessment scale (Table S1)}

A study can be awarded a maximum of one star for each numbered item within the selection and outcome categories. A maximum of two stars can be given for comparability.

\section{Selection}

(I) Representativeness of the exposed cohort:

(i) Truly representative of the average patients presenting with acute type A dissection in the community*;

(ii) Somewhat representative of the average patients presenting with acute type A dissection in the community*;

(iii) Selected group of users e.g., nurses, volunteers;

(iv) No description of the derivation of the cohort.

(II) Selection of the non exposed cohort:

(i) Drawn from the same community as the exposed cohort*;

(ii) Drawn from a different source;

(iii) No description of the derivation of the non exposed cohort.
(III) Ascertainment of exposure:

(i) Secure record (e.g., surgical records)*;

(ii) Structured interview*;

(iii) Written self report;

(iv) No description.

(IV) Demonstration that outcome of interest was not present at start of study:

(i) $\mathrm{Yes}^{*}$;

(ii) No.

\section{Comparability}

Comparability of cohorts on the basis of the design or analysis:

(I) Study controls for age, gender, pre-operative comorbidities*;

(II) Study controls for any additional pre-operative and intra-operative factors*.

\section{Outcome}

(I) Assessment of outcome:

(i) Independent blind assessment*;

\begin{tabular}{llllll}
\multicolumn{6}{l}{ Table S1 Newcastle-Ottawa Scale on three levels: selection, comparability, and outcome } \\
\hline Study & First author & Selection & Comparability & Outcome & Total score \\
\hline 1 & Shi & 4 & 2 & 2 & 8 \\
\hline 2 & Ohtsubo & 4 & 1 & 2 & 7 \\
3 & Tan & 4 & 2 & 2 & 8 \\
\hline 4 & Uchida & 4 & 1 & 2 & 7 \\
\hline 5 & Rylski & 4 & 2 & 3 & 9 \\
\hline 6 & Kim & 4 & 2 & 3 & 9 \\
7 & Shiono & 4 & 2 & 2 & 8 \\
\hline 8 & Zhang & 4 & 1 & 2 & 7 \\
9 & Sun & 4 & 2 & 2 & 8 \\
10 & Di Eusanio & 4 & 2 & 3 & 8 \\
\hline 11 & Rice & 4 & 2 & 3 & 9 \\
12 & Omura & 4 & 2 & 2 & 9 \\
13 & Vallabhajosyula & 4 & 1 & 2 & 7 \\
\hline 14 & Dai & 4 & 1 & 7 \\
\hline
\end{tabular}


(ii) Record linkage*;

(iii) Self report;

(iv) No description.

(II) Was follow-up long enough for outcomes to occur:

(i) Yes (at least 5 years of follow up period for outcome of interest) ${ }^{*}$;

(ii) No.
(III) Adequacy of follow up of cohorts:

(i) Complete follow up-all subjects accounted for*;

(ii) Subjects lost to follow up unlikely to introduce bias-small number lost; $\leq 10 \%$ loss of follow up*;

(iii) Follow up rate $>90 \%$ and no description of those lost;

(iv) No statement. 